\title{
Kinerja Kelompok Tani dalam Pengelolaan Hutan Tanaman Rakyat di Desa Bacu-
}

\section{Bacu Kabupaten Barru}

\author{
Ridwan ${ }^{1}$, Mas'ud Junus ${ }^{1}$, M. Asar Said Mahbub ${ }^{1}$, Restu Puput Windarti ${ }^{1}$ \\ ${ }^{1}$ Fakultas Kehutanan, Universitas Hasanuddin, Makassar \\ *Email:riwaf@yahoo.com
}

\begin{abstract}
This study aims to describe the performance of farmer groups in forest management before and after the determination of Community Timber Plantation called HTR. This research conducted by diagnostic study and interview. The results show that through HTR activities it has a positive impact on all farmer performance in terms of farmer group institutional activities and land management activities on state forest land which in the case of this research are production forest.
\end{abstract}

Keywords: Farmer groups, forest management, HTR, performance DOI: http://dx.doi.org/10.24259/jhm.v10i2.4108

\section{PENDAHULUAN}

Pengelolaan hutan merupakan suatu usaha yang didalamnya meliputi beberapa aspek seperti, perencanaan hutan, organisasi pelaksanaan, implementasi, monitoring dan evaluasi yang setiap fungsi saling berkaitan dan merupakan satu kesatuan yang saling mempengaruhi (Arief, 2001). Pengelolaan hutan berbasis kemasyarakatan diharapkan dapat meningkatkan taraf perekonomian masyarakat, meningkatkan lapangan kerja, serta membantu kelestarian hutan secara berkelanjutan (Arief, 2001). Ahmad, dkk (2017) berpendapat bahwa kunci pengelolaan hutan membutuhkan kesadaran masayarakat untuk mengelola sumber daya hutan dengan menyeimbangkan antara kepentingan finansial dengan aspek pengelolaan secara lestari dan utuh. Salah satu bentuk pengelolaan hutan yang sejalan dengan prinsip di atas adalah program pembangunan Hutan Tanaman Rakyat atau yang sering disingkat dengan HTR (Mas'ud, dkk., 2011).

Peraturan Menteri Lingkungan Hidup dan Kehutanan Republik Indonesia Nomor P.83/Menlhk/Setjen/Kum.1/10/2016 menjelaskan bahwa Hutan Tanaman Rakyat yang selanjutnya disingkat HTR adalah hutan tanaman pada hutan produksi yang dibangun oleh kelompok masyarakat untuk meningkatkan potensi dan kualitas hutan produksi dengan menerapkan silvikultur dalam rangka menjamin kelestarian sumber daya hutan. Program HTR pada dasarnya bersifat multi-sektor, multi-pihak, dan multistrata pemerintah yang memiliki kerangka dalam meyeimbangkan kebutuhandan ketersediaan sumberdaya hutan dengan berpedoman pada asas pelestarian (Ahmad, dkk., 2017).

Salah satu diantara 13 kabupaten di Provinsi Sulawesi Selatan yang mendapat jatah menyediakan HTR adalah Kabupaten Barru. Berdasarkan data yang telah di verifikasi oleh Balai Pemantauan Pemanfaatan Hutan Produksi (BP2HP) pada tahun 2014, Kabupaten Barru memiliki potensi hutan produksi yang dapat dikelolah dengan baik untuk kepentingan pengembangan HTR yaitu seluas 5.240 ha dengan 136 IUPPHKHTR koperasi/perorangan dengan total areal seluas 1.281 ha (BP2HP, 2015).

Berdasarkan pencapaian tujuan, HTR yang dicadangkan di areal Desa Bacu-Bacu potensial dalam memberikan kontribusi terhadap pembangunan daerah dan masyarakat khususnya di bidang peningkatan pendapatan masyarakat, penyerapan tenaga kerja dan jasa lingkungan (Mas'ud, dkk., 2011). Walaupun demikian, keberhasilan suatu program cenderung diukur dari sisi penghidupan masyarakat dan masih kurang literasi terkait dinamika sosial akibat intervensi suatu program-program pemerintahan utamanya di bidang 
kehutanan. Oleh karena itu penelitian ini mencoba mengkaji dinamika kinerja kelompok tani akibat masuknya program HTR di Desa Bacu-Bacu Kabupaten Barru.

\section{METODE PENELITIAN}

\subsection{Waktu dan Tempat}

Penelitian dilaksanakan pada bulan Maret sampai April 2017. Lokasi penelitian terletak di Desa BacuBacu, Kecamatan Pujananting, Kabupaten Barru Provinsi Sulawesi Selatan.

\subsection{Teknik Pengambilan Data}

Adapun teknik pengambilan data dilakukan dengan cara:

a. Studi diagnostik yaitu studi pengenalan awal lokasi penelitian berupa literatur dan diskusi dengan pihak yang pernah mengunjungi lokasi, selanjutnya dilakukan observasi lapangan dengan cara melihat langsung situasi kondisi yang ada dilapangan guna mendapatkan gambaran nyata dari objek yang akan diteliti.

b. Wawancara digunakan untuk memperoleh data informasi dengan menggunakan sensus. Sensus dilakukan dengan melakukan pendataan (pengumpulan data) pada semua anggota kelompok tani hutan tanaman rakyat (KTH-HTR). Sebagaimana diketahui nama KTH-HTR di lokasi penelitian bernama KTH Padang Pobbo. V

Data yang dikumpulkan dalam penelitian ini terdiri dari dua jenis yaitu data primer dan data sekunder.

a. Data primer diperoleh dengan cara survei lapangan melalui wawancara kepada responden (semua anggota kelompok tani Padang Pabbo) yang berjumlah 18 orang. Wawancara dilakukan dengan panduan kuisioner (lembar pertanyaan) yang menganalisis kinerja kelompok tani berdasarkan variabel spesifik yaitu eksistensi kelompok, struktur kelompok, peraturan kelompok, rencana kerja kelompok, keanggotaan kelompok dan areal kelola kelompok.

b. Data sekunder adalah data yang diperoleh dari instansi dan laporan atau informasi lainnya yang berakaitan dengan penelitian. Data sekunder meliputi data potensial areal HTR, keadaan umum lokasi, kondisi sosial, ekonomi, serta data pendukung lainya yang dianggap kontekstual dengan penelitian ini.

\subsection{Analisis Data}

Penelitian mengenai kinerja mengambil beberapa variabel kriteria penilaian yang dilaksanakan oleh Food Agriculture Organization yang diuraikan dalam publikasi Global Forest Resource Assessment pada tahun 2011. Variabel tersebut kemudian dikontekskan dengan kondisi yang terjadi di tingkat tapak lokasi penelitian. Adapun analisis data yang digunakan dalam peneitian ini adalah analisis kuantitatif dan analisis kualitatif yang diuraikan sebagai berikut:

a. Analisis Kuantitatif

Menilai hasil wawancara dengan pemberian skor terhadap jawaban respondevvn dengan skala $5: 4: 3$ :

$2: 1$ kemudian diolah menggunakan rumus dan diberi nilai skoring yang sudah di tetapkan. diadaptasi dari Akhdiyat dan Riyani (2009)

Mengetahui TKKT setiap variabel

$$
\text { TKKT }=\frac{\sum s+k}{n s+1 \times n^{2}} \times 100 \%
$$

Mengetahui TKKT total

$$
\text { TKKT total }=\frac{\sum N K T}{\sum \operatorname{sir}} \times 100 \%
$$

Keterangan:

TKKT = Tingkat Kinerja Kelompok Tani 


$$
\begin{aligned}
& \text { SrI = Skor ideal } \\
& \operatorname{Sr} R \quad=\text { Skorriil } \\
& \operatorname{Sr} T=\text { Skor total } \\
& R \quad=\text { Jumlah responden } \\
& N \quad=\text { jumlah indikator variable }
\end{aligned}
$$

Kriteria tingkat kinerja kelompok tani (TKKT) berdasarkan nilai skoring di tetapkan sebagai berikut:

1. Nilai TKKT $0 \%-20 \%$ maka kelompok tani berkinerja sangat rendah

2. Nilai TKKT $20 \%-40 \%$ maka kelompok tani berkinerja rendah

3. Nilai TKKT $40 \%-60 \%$ maka kelompok tani berkinerja sedang

4. Nilai TKKT $60 \%-80 \%$ maka kelompok tani berkinerja tinggi

5. Nilai TKKT $80 \%-100 \%$ maka kelompok tani berkinerja sangat tinggi

b. Analisis kualitatif

Analisis kualitatif dilakukan dalam penjabaran deskripsi kinerja kelompok tani berupa kondisi detail terkait eksistensi kelompok, struktur kelompok, peraturan kelompok, rencana kerja kelompok, keanggotaan kelompok dan areal kelola kelompok. Deskripsi kinerja kelompok tani yang telah dianalisis kemudian dielaborasi dengan beragam pendapat ahli.

\section{HASIL DAN PEMBAHASAN}

\subsection{Kinerja Kelompok Tani dalam Pengelolaan HTR}

Pengukuran kinerja kelompok tani pada tahap awal diukur dengan mengkaji sejauh mana aktifitas masyarakat dalam berlembaga sebagai kelompok dalam konteks sebelum dan sesudah penetapan skema pengelolaan HTR. Hasil penelusuran terkait variabel-variabel yang dapat diukur adalah kondisi kelompok secara umum, dinamika yang terjadi dalam struktur kelompok, kondisi aturan kelompok, adanya rencana kerja kelompok, kondisi keanggotaan kelompok dan bagaimana areal kelola kelompok.

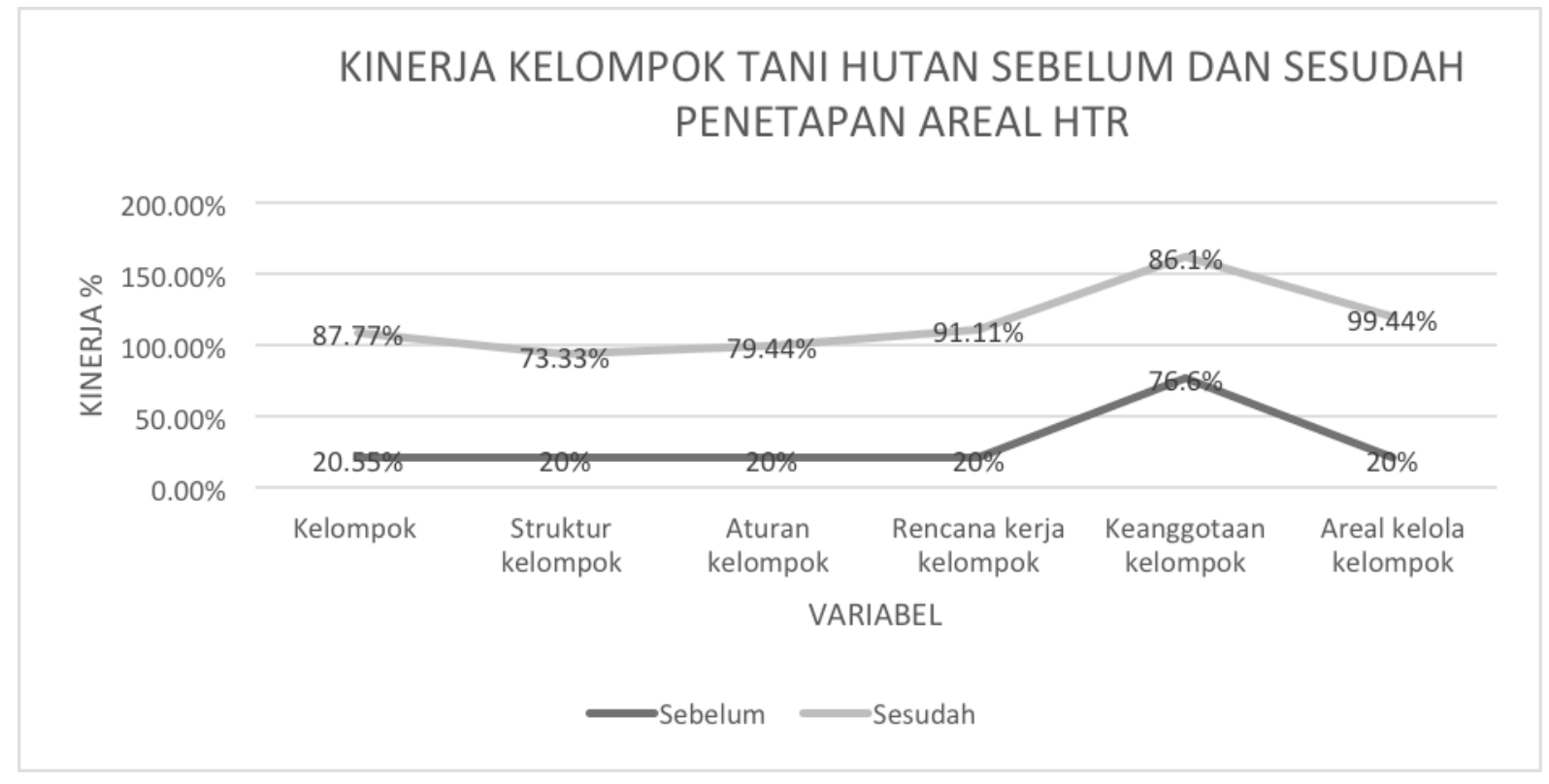

Gambar 1. Grafik kinerja kelompok tani sebelum dan sesudah penetapan HTR

Gambar 1 menunjukkan terjadi perubahan positif secara signifikan terhadap seluruh variabel yang diteliti terkait konteks sebelum dan sesudah penetapan HTR di lokasi penelitian. Kinerja kelompok tani 
学

Jurnal Hutan dan Masyarakat. Vol. 10(2): 231-238, Desember 2018

Diserahkan: 2018-05-06; Diterima: 2018-12-25

ISSN: 1907-5316 ISSN ONLINE: 2613-9979

masing-masing variabel mengalami peningkatan akibat adanya penetapan areal HTR. Pada tahap awal ketika masih berbentuk kelompok tani pertanian dan perkebunan, kondisi kinerja kelompok tani di lokasi lahan hutan negara, yang saat ini dikelola menjadi lahan HTR, belum menarik masyarakat untuk dikelola.

Kondisi di atas terjadi karena status kepemilikan lahan di atas yang masih dianggap belum jelas, aksesibilitas rendah dan kondisi kesuburan lahan yang menyebabkan varietas tanaman yang dapat dikelola cenderung terbatas. Hal tersebut sesuai dengan pendapat Amin (2017) yang menyebutkan bahwa kondisi lahan yang layak secara ekonomi dan sosial serta adanya kepastian hak terhadap lahan menjadi preferensi utama masyarakat melakukan proses pengelolaan lahan terutama yang mengembangkan komoditas kehutanan.

\subsection{Kelompok Tani}

Adanya legalitas KTH mengelola hutan negara dapat terlihat melalui Surat Keputusan Pemberian IUPHHK-HTR kepada KTH Padang Pobbo. Kelompok tani ini beranggotakan 18 orang yang telah diverifikasi identitasnya pada tanggal 11 Juli 2009 dengan Nomor 028/DB/VII/2009 dan semuanya merupakan masyarakat yang berdomisili di Desa Bacu-Bacu Dusun Ampiri.

Peningkatan nilai kinerja pada variabel kelompok meningkat dari $20,55 \%$ menjadi $87,77 \%$. Hal ini disebabkan karena terjadi perubahan animo masyarakat yang awalnya beraktifitas di kawasan hutan negara secara illegal kini diberikan kesempatan mengelola secara sah.

Pemberian legalitas formal berupa Izin Usaha Pemanfaatan hasil Hutan Kayu (IUPHHK) kepada KTH Padang Pobbo memicu perhatian khusus pemerintah daerah (pemda) Kabupaten Barru kepada masyarakat yang tergabung ke dalam kelompok tani. Implikasinya, terdapat program-program berupa pertemuan, sosialisasi, penyuluhan, dan pelatihan sehingga memicu meningkatnya aktifitas masyarakat di dalam KTH.

Hal tersebut di atas sangat berbeda dengan aktifitas masyarakat sebelumnya. Organisasi masyarakat yang tergabung dalam KTH juga membentuk sebuah kelompok tani pertanian dan perkebunan. Namun dinamika di dalam kelompok tersebut tidak seintensif ketika telah menjadi KTH.

Sebelum terbentuknya KTH, masyarakat yang juga tergabung dalam kelompok tani pertanian dan perkebunan lebih memfokuskan pengelolaan lahannya dengan komoditas pertanian dan perkebunan. Hal di atas perlahan mengalami perubahan selama program HTR diinisiasi. Perubahan perilaku mulai terjadi pada lahan hutan negara dimana insentif program pemerintah memfokuskan pada sektor kehutanan.

\subsection{Struktur Kelompok}

Kinerja kelompok tani juga diukur melalui dinamika struktur kelompok. Melalui analisis terhadap variabel ini dapat dilihat perubahan-perubahan yang terjadi dalam struktur kelompok melalui pembagian peran dan tanggung jawab petani di dalam struktur kelompok tani sebelum dan setelah terbentuknya KTH Padang Pobbo.

Hasil penelitian menunjukkan bahwa terjadi peningkatan nilai skor dari $20 \%$ menjadi sebesar $73,33 \%$. Hal ini terjadi karena adanya perubahan perombakan pengisi struktur organisasi dalam kelompok. Perubahan di atas terjadi diikuti oleh peningkatan tingkat keaktifan penanggung jawab pengelola KTH.

Perubahan ini dilaksanakan secara partisipatif yang melibatkan seluruh anggota masyarakat melalui kegiatan musyawarah. Hasil musyawarah membuat sebuah inovasi bahwa pengisi struktur adalah orangorang yang memiliki pengalaman organisasi dan memiliki pengalaman melaksanakan aktifitas memproduksi tanaman kehutanan.

Walaupun demikian, perubahan pengisi struktur tidak diikuti oleh perubahan sistem di dalam struktur organisasi. Struktur KTH Padang Pobbo hanya terdiri dari komponen inti yaitu ketua, sekertaris, bendahara beserta anggota dan tidak memiliki komponen pendukung seperti seksi-seksi atau koordinator bidang. Hal ini tidak mengalami perubahan dari struktur kelompok sebelum terbentuknya KTH Padang Pobbo. 
瓷

Jurnal Hutan dan Masyarakat. Vol. 10(2): 231-238, Desember 2018

Diserahkan: 2018-05-06; Diterima: 2018-12-25

ISSN: 1907-5316 ISSN ONLINE: 2613-9979

\subsection{Peraturan Kelompok}

Sebelum penetapan areal HTR, aturan kelompok memperoleh nilai skor 20\%. Hal ini disebabkan karena tidak adanya aturan kelompok secara formal yang mendukung. Aturan kelompok pada tahap awal sebelum terbentuknya KTH masih berupa Surat Keterangan. Melalui program HTR kemudian mewajibkan adanya penyusunan Anggaran Dasar dan Anggaran Rumah Tangga (AD/ART) yang kemudian didukung oleh aturan kelompok yang memperjelas AD/ART dan rencana kerja yang telah disusun sebelumnya.

Sebelum masuknya program HTR, masyarakat/petani hutan tidak menyusun atau merancang mengenai aturan-aturan kelompok karena pada saat itu kelompok tani masih berupa kelompok yang diinisiasi oleh pihak-pihak yang mengurusi pertanian dan perkebunan. Selain itu para petani hutan tidak mengiginkan adanya aturan yang mengikat karena dengan tidak adanya aturan para petani hutan menganggap bisa bebas masuk dan menerima apabila ada tawaran dalam kegiatan pengelolaan. Aturan kelompok pada saat itu hanya berupa kesepakatan-kesepakatan yang dibuat pada saat kegiatan akan berjalan.

Setelah terbentuknya KTH, legalitas masyarakat dalam memanfaatkan kawasan hutan menjadi terukur. Hal ini disebabkan karena masyarakat telah memiliki aturan formal dalam bentuk AD/ART dan aturan internal kelompok dalam bentuk pembagian peran anggota, sanksi-sanksi (baik secara formal maupun informal) dan aturan bagi hasil.

\subsection{Rencana Kerja Kelompok}

Berdasarkan data yang disajikan pada Gambar 1 sebelum penetapan areal HTR variabel rencana kerja kelompok menunjukan nilai skor $20 \%$. Hal ini disebabkan sebelum penetapan areal HTR masyarakat/petani hutan tidak menyusun rencana kerja yang memiliki jadwal pelaksanaan yang bersifat tetap sebagai pedoman pengarahan kegiatan dalam rangka mencapai tujuan dan hasil yang dinginkan.

Penyusunan rencana kerja hanya disusun oleh ketua yang pada saat itu menjadi ketua kelompok dan tidak dimusyawarahkan dengan anggota yang lain. Dalam membuat rencana kerja dan menjalankan aktivitasnya hanya berpatokan pada ramalan cuaca yang telah dijalankan sejak lama dan tidak terurai dalam bentuk dokumen rencana kerja.

Setelah penetapan areal HTR nilai skor meningkat sebesar 91,11\%. Hal ini disebabkan KTH Padang Pobbo telah memiliki rencana kerja dalam bentuk dokumen. Isi dari rencana kerja itu sendiri berupa rincian program kegiatan dan pelaksana tugas yang telah dilengkapi dengan jadwal pelaksanaan. Dalam penyusunan rencana kerja semua anggota KTH Padang Pobbo beserta stake holder dan aparat Desa setempat ikut berpartisipasi dalam musyawarah penyusunan program-program kegiatan yang akan dijalankan kedepannya. Dengan adanya program kerja yang telah disusun dan disepakati KTH menjadi lebih terarah dan memiliki tujuan.

\subsection{Keanggotaan Kelompok}

Berdasarkan data yang disajikan Gambar 1 menunjukan bahwa variabel keanggotaan kelompok sebelum penetapan areal HTR memperoleh nilai skor $76.6 \%$. Hal ini dikarenakan sebelum penetapan areal HTR, kelompok tani sebelumnya telah aktif dalam melakukan kegiatan pengelolaan seperti menanam tanaman tahunan maupun musiman untuk memenuhi kebutuhan hidup.

Setelah penetapan areal HTR nilai skor meningkat menjadi 86.1\%. Hal ini disebabkan setelah adanya rencana kerja dan Surat Keputusan Pemberian IUPHHK-HTR oleh KTH Padang Pobbo yang membuat masyarakat yang tadinya tidak ikut mengelola di kawasan hutan negara kemudian ikut bergabung menjadi anggota KTH dan mendapatkan akses legal mengelola lahan hutan negara. Jadi dapat disimpulkan bahwa tingkat partisipasi masyarakat desa semakin meningkat dalam mengelola hutan negara karena adanya legalitas yang diberikan oleh negara kepada KTH Padang Pobbo. 


\subsection{Areal Kelola}

Gambar 1 memaparkan variabel areal kelola sebelum penetapan areal HTR memperoleh nilai skor $20 \%$. Hal ini disebabkan masyarakat/petani hutan yang berada disekitar hutan telah melakukan kegiatan pengelolaan diluar maupun didalam kawasan hutan. Masyarakat/petani hutan hanya membuka lahan yang dijadikan areal kelola dengan luas lahan yang berbeda satu sama lainnya tanpa ada surat izin kelola. Adapun kegiatan pengelelolaannya seperti melakukan aktifitas menanam pohon yang diperuntukkan sebagai bahan bangunan selain itu kegiatan berkebun dan bertani juga dilakukan demi memenuhi kebutuhan hidup.

Gambar 1 menunjukkan sesudah penetapan arael HTR nilai skor yang diperoleh meningkat sebesar 99.44\%. Hal ini disebabkan setelah penetapan areal HTR petani hutan yang tergabung dalam KTH Padang Pobbo telah memiliki Surat Keputusan Pemberian IUPHHK-HTR. Diketahui bahwa anggota KTH Padang Pobbo yang berjumlah 18 orang, semua telah mendapakat SK pengelolaan yang telah disahkan. Untuk skema pembagian areal kelola KTH Padang Pobbo tidak mendapatkan luas areal yang sama melainkan sesuai dengan umur sepertiyang di kemukakan Birgantoro, dkk (2007) bahwa usia mempengaruhi tingkat pemanfaatan sumberdaya hutan. Semakin tua usia seseorang maka semakin kurang produktif, sehingga pemanfaatan sumberdaya hutan yang ada juga relatif kecil.

\subsection{Kinerja Kelompok Tani dalam Proses Pengelolaan HTR}

\section{KINERJA KELOMPOK TANI DALAM PROSES PENGELOLAAN HUTAN SEBELUM DAN SESUDAH DITETAPKANYA SEBAGAI AREAL HTR}

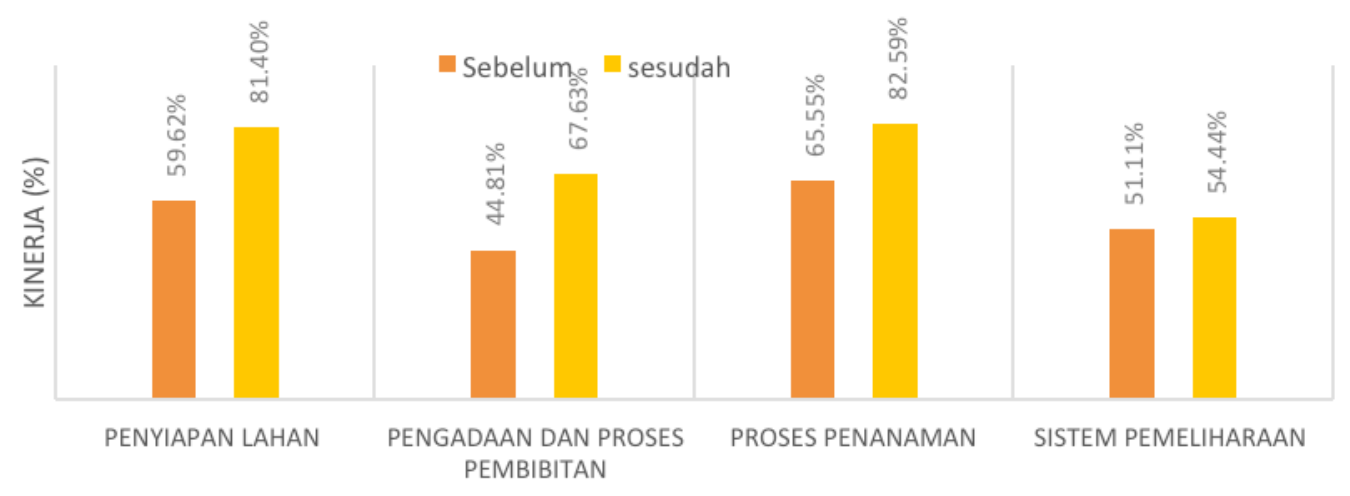

Gambar 2. Grafik Kinerja Dalam Proses Pengelolaan Lahan Hutan

\subsection{Penyiapan Lahan}

Gambar 2 menunjukkan bahwa variabel penyiapan lahan sebelum penetapan areal HTR memiliki nilai skor $59,62 \%$. Kegiatan penyiapan dan pengolahan lahan telah dilaksanakan sebelum adanya penetapan HTR melalui kegiatan budidaya tanaman padi (Oryza sativa), pisang (Musa paradisiaca), coklat (Theobroma cacao), kemiri (Aleurites moluccanus), aren (Arenga pinnata), jati lokal (Tectona grandis), jati putih (Gmelina arborea) dan mangga (Mangifera indica). Kegiatan penyiapan lahan. Namun, tidak seluruh lahan digarap karena keterbatasan kemampuan mengelola lahan secara intensif.

Setelah adanya penetapan HTR, masyarakat kemudian mengoptimalkan hak kelolanya masing-masing sehingga lahan yang mampu digarap dan dikelola mencapai $81,04 \%$. Peningkatan ini didukung oleh kebutuhan untuk mengelola lahan untuk kebutuhan budidaya tanaman kehutanan tidak seintensif tanaman semusim. Hal tersebut diatas sesuai pula dengan pendapat Mas'ud, dkk (2011) yang memaparkan bahwa salah satu bentuk kemudahan mengelola tanaman kehutanan adalah intensitas pengelolaan tanaman yang 
paling banyak berada dalam jangka waktu tiga tahun pertama, dan apabila dibandingkan dengan tanaman semusim pengelolaannya relatif lebih mudah.

Pembersihan lahan diketahui dilakukan secara gotong royong dengan pembabatan semak dan gulma kemudian dilakukan penyemprotan agar gulma benar benar mati. Kemudian pengemburan tanah juga dilakukan sebelum melaksanakan penanaman. Pembuatan lubang tanam dilakukan juga sudah mendapat arahan dari penyuluh bahwa ukuran lubang tanam setiap tanaman berbeda-beda. Lubang tanam dibuat tergantung jenis tanamannya tetapi rata-rata dilahan ini telah dibuat lubang tanam dengan ukuran $30 \mathrm{~cm} \times 30$ $\mathrm{cm} \times 30 \mathrm{~cm}$.

\subsection{Pengadaan Dan Proses Pembibitan}

Pengadaan dan proses pembibitan sebelum penetapan areal HTR menunjukkan nilai skor $44,81 \%$. Pada lahan hutan negara yang saat itu belum memiliki akses legal telah diletakkan lokasi pembenihan dan pembibitan oleh masyarakat melalui kegiatan Kebun bibit Rakyat (KBR). Penempatan lokasi ini merupakan kesatuan lokasi masyarakat di Desa Bacu-Bacu sehinnga memehui luasan lahan yang cukup luas di dalam kawasan hutan negara.

Akses masyarakat dalam membeli bibit masih rendah sebelum adanya penetapan areal HTR namun diwaktu yang bersamaan ini masyarakat telah memiliki akses meminta dan membeli benih bibit tabnaman kehutanan serta memiliki keterampilan mengelola benih sehingga menjadi bibit yang baik.

Setelah adanya penetapan areal HTR nilai skor meningkat sebesar $67,63 \%$. Hal ini dikarenakan telah adanya lahan lokasi pembibitan yang disiapkan oleh KTH Padang Pobbo untuk menyimpan bibit-bibit yang berasal dari proses pembenihan KBR (setelah berakhirnya KBR masyarakat tetap melakukan proses pembibitan) dan adanya tambahan bibit tambahan yang berasal dari pemerintah. Kondisi lainnya berupa akses pembelian bibit di luar desa masih tetap rendah karena hanya di desa ini yang konsisten melakukan proses pembenihan yang menghasilkan bibit baru.

\subsection{Proses Penanaman}

Proses penanaman sebelum penetapan areal HTR memperoleh nilai skor $65,55 \%$. Hal ini disesabkan sebelum penetapan areal HTR diketahui proses penanaman yang dilakukan masyarakat/petani hutan sudah mengetahui tentang aturan jarak tanam yang diperoleh dari pengalaman-pengalaman sebelumnya. Waktu tanamam masyarakat/petani hutan hanya mengadalkan mengenai ramalan cuaca saja. Hal ini dikarenakan tidak adanya dokumen rencana kerja masyarakat/petani hutan yang bisa dijadikan acuan. Komposisi tanaman sendiri lebih banyak membudidayakan tanaman perkebunan dan pertanian, yang diharapkan lebih cepat proses pemanenannya dan mudah untuk mendapatkan bibit.

Setelah penetapan areal HTR nilai skor yang diperoleh meningkat sebesar $82,59 \%$. Hal ini disebabkan telah adanya dukumen rencana kerja yang menjadi acuan KTH Padang Pobbo. Proses penyusunan ini melibatkan seluruh anggota kelompok dan penyuluh kehutanan yang dianggap representatif sebagai ahli dalam membudidayakan tanaman kehutanan. Hasil diskusi menunjukkan bahwa komposisi tanaman sesudah penetapan tanaman kehutanan. Komposisi tanaman kehutanan adalah sebesar $60 \%$ dan $40 \%$ adalah tanaman perkebunan jangka pendek. Kondisi ini hampir selaras dengan araha pemanfaatan lahan melalui penelitian Mas'ud, dkk (2011) yang membangun model pengelolaan HTR di desa ini yakni pemanfaatan agroforestri tanaman kehutanan berupa sengon (Paraserianthes falcataria L), jabon (Anthocephalus cadamba), dan mahoni (Swietenia mahagoni) dengan tanaman jangka pendek berupa kacang tanah (Arachis hypogaea).

\subsection{Sistem Pemeliharaan}

Sistem pemeliharaan sebelum penetapan areal HTR memperoleh nilai skor sebesar $51,11 \%$. Hal ini disebabkan karena masyarakat telah melakukan proses perawatan yang cukup intensif pada tahun pertama hingga tahun ketiga. Proses pemantauan tanaman yang membutuhkan penambalan juga dilakukan dalam memaksimalkan penggunaan. Sistem pemeliharaan yang dilakukan masih terbatas pembersihan gulma dan 
pemberian pupuk. Setelah penetapan HTR peningkatan tidak bertambah secara signifikan. Sistem pemeliharaan yang bertambah adalah penggemburan tanah 2 bulan sekali yang dilaksanakan pada tahun pertama serta melakukan proses pemangkasan yang dilaksanakan pada tahun ketiga dan keempat sesuai arahan penyuluh kehutanan. Kondisi ini menghasilkan hasil skor senilai $55,77 \%$.

\section{KESIMPULAN}

Melalui aktifitas HTR memberikan dampak positif terhadap seluruh kinerja petani dalam hal aktifitas kelembagaan kelompok tani dan aktifitas pengelolaan lahan yang baik di lahan hutan negara yang dalam kasus penelitian ini adalah hutan produksi terbatas.

\section{DAFTAR PUSTAKA}

Ahmad, F., Yusran, Y., \& Mas' ud, E. I. 2017. Penilaian Aspek Hukum Tata Kelola Hutan Tanaman Rakyat di Kabupaten Barru. Jurnal Hutan dan Masyarakat, 9(1), 8-16.

Amin, A. S., \& Mas' ud, E. I. (2017). Preferensi Masyarakat terhadap Pola Pemanfaatan Lahan Hutan Rakyat di Desa Lekopancing, Kecamatan Tanralili, Kabupaten Maros. Jurnal Hutan dan Masyarakat, 9(2), 131135.

Arief, A. 2001. Hutan dan Kehutanan. Kanisius, Yogyakarta.

[FAO] Food Agriculture Organization. 2001. Global Forest Resource Assessment 2000. Rome: Food Agriculture Organization of the United Nations.

Fisher, M., Maryudi, A., \& Sahide, M. (2017). Forest and Society: Initiating a Southeast Asia Journal for Theoretical, Empirical, and Regional Scholarship. Forest and Society, 1(1), 1-7. doi:http://dx.doi.org/10.24259/fs.v1i1.1369

Moeliono, M., Thuy, P., Waty Bong, I., Wong, G., \& Brockhaus, M. (2017). Social Forestry - why and for whom? A comparison of policies in Vietnam and Indonesia. Forest and Society, 1(2), 78-97. doi:http://dx.doi.org/10.24259/fs.v1i2.2484

Widiyanti, S. Studi Kelembagaan Kelompok Tani Hutan Rakyat di Wilayah Cianjur Selatan (Kasus Di Kecamatan Cibinong Dan Tanggeung). Fakultas Kehutanan. Institut Pertanian Bogor. Bogor 